\title{
UNJUK KERJA DOWN-FLOW HANGING SPONGE (DHS) BIOREAKTOR SEBAGAI SECONDARY TREATMENT UNTUK PENGOLAHAN LIMBAH DOMESTIK
}

\section{Performance of Down-Flow Hanging Sponge (DHS) Bioreactor as A Secondary Treatment for Domestic Wastewater Treatment}

Faisal $^{{ }^{1}}$, Izarul Machdar ${ }^{1}$, Syaifullah Muhammad ${ }^{1}$, Takashi Onodera ${ }^{2}$, Kazuaki Syutsubo ${ }^{2}$, dan Akiyoshi Ohashi ${ }^{3}$

1. Jurusan Magister Teknik Kimia, Fakultas Teknik, Universitas Syiah Kuala Jl. Tgk. Syech Abdurrauf No. 7, Banda Aceh, 23111, Indonesia

2. Center of Regional Environmental Research, National Institute for Environmental Studies (NIES), Tsukuba, Ibaraki 305-8506, Japan

3. Department of Civil and Environmental Engineering, Hiroshima University 1-4-1 Kagamiyama, Higashihiroshima, 739-8527, Japan

*e-mail: faisal.0732@gmail.com

\section{ABSTRAK}

Pencemaran air limbah akan terus bertambah dengan meningkatnya jumlah penduduk dan aktifitas masyarakat. Berbagai proses telah diaplikasikan untuk pengolahan limbah domestik, tetapi umumnya proses-proses tersebut membutuhkan biaya operasi dan perawatan yang relatif mahal. Downflow Hanging Sponge (DHS) telah diusulkan sebagai pemecahan persoalan penanganan limbah domestik untuk negara-negara berkembang. DHS bioreaktor adalah pengolahan limbah secara biologis yang tidak membutuhkan aerator dan mudah dalam pengoperasian. Penelitian ini bertujuan untuk mengevaluasi bioreaktor DHS sehingga dapat diterapkan di Indonesia. Bioreakor DHS dioperasikan dengan hydraulic retention time (HRT) 4 jam. Hasil penelitian menunjukkan DHS bioreaktor mampu mengurangi hingga 34\% Chemical Oxygen Demand (COD) total, 33\% soluble Chemical Oxygen Demand (COD), 80\% Biological Oxygen Demand (BOD) total, dan 65\% ammonia.

Kata kunci: Limbah domestik, down-flow hanging sponge (DHS), hydraulic retention time (HRT)

\section{ABSTRACT}

Wastewater pollution will continue to grow as the population and community activities continue to increase. Various techniques have been applied for domestic waste treatment, but generally these processes require relatively high operation and maintenance costs. Down Flow Hanging Sponge (DHS) has been proposed as a solution to the problem of handling domestic waste for developing countries. DHS bioreactor is a biological waste treatment that does not require an aerator and is easy to operate. This study aims to evaluate DHS bioreactors that can be applied in Indonesia. DHS bioreactor is operated with 4 hours hydraulic retention time (HRT). The results showed that DHS bioreactor is able to reduce up to 34\% Chemical Oxygen Demand (COD) total, 33\% soluble Chemical Oxygen Demand (COD), 80\% Biological Oxygen Demand (BOD) total, and 65\% Ammonia.

Keywords: Domestic wastewater, down-flow hanging sponge (DHS), hydraulic retention time (HRT)

\section{PENDAHULUAN}

Berdasarkan ketentuan PP No. 82 tahun 2001 yang bertujuan untuk menjaga kualitas badan air, maka ditetapkan keputusan Menteri Negara Lingkungan Hidup No. 112 tahun 2003 tentang baku mutu air limbah domestik. Di dalam 
peraturan tersebut dikatakan bahwa setiap penanggung jawab usaha dan atau kegiatan permukiman (real estate), rumah makan, perkantoran, perniagaan dan apartemen wajib melakukan pengolahan air limbah domestik sehingga mutu air limbah yang dibuang ke lingkungan tidak melampaui baku mutu air limbah domestik yang telah ditetapkan.

Sampai saat ini, sistem sanitasi seperti halnya toilet keluarga dan septik tank komunal yang telah dibangun tidak dapat menjamin bahwa konsentrasi effluen yang dihasikan akan memenuhi standar kualitas yang dapat dibuang ke permukaan air. Ambang batas air limbah dari hasil pengolahan limbah yang telah ditentukan oleh Pemerintah Indonesia adalah BOD $100 \mathrm{mg} / \mathrm{L}$, TSS $100 \mathrm{mg} / \mathrm{L}$, minyak dan lemak $10 \mathrm{mg} / \mathrm{L}$, dan $\mathrm{pH} 6$ - 9 (Peraturan Menteri Lingkungan Hidup No. 5 Tahun 2014 tentang Standar Kualitas Air Limbah Domestik).

Domestic Waste Treatment (DWT) atau Instalasi Pengolahan Air Limbah (IPAL) seperti yang dilakukan saat ini adalah proses yang memerlukan energi. Pada tahun 2012 hanya ada dua belas instalasi pengolahan air limbah kota terpusat di Indonesia yang mampu melayani $1 \%$ dari populasi penduduk (Kearton et al., 2013). Sistem yang digunakan adalah UASB (Upflow Anaerobic Sludge blanket), Rotating BioContactors (RBC), dan lumpur aktif (Kearton et al., 2013) .

Energi yang paling umum dibutuhkan untuk IPAL adalah menyediakan oksigen untuk pengolahan biologis seperti kolam aerobik, filter menetes, atau kontaktor biologis berputar. Sekitar $60-70 \%$ dari total energi yang disuplai ke IPAL itu umumnya digunakan untuk aerasi. Dapat disimpulkan yang menjadi masalah pada pengolahan limbah dengan kolam aerobik tersebut adalah keterbatasan penyediaan dana pada pengoperasian, kebutuhan aerator tambahan dan lain sebagainya. Permasalahan di atas menjadi sebuah gagasan dari penelitian ini yaitu pengolahan limbah cair domestik menggunakan bioreaktor Downflow Hanging Sponge (DHS). Pada reaktor DHS, oksigen secara alami dipasok langsung dari atmosfer (Tandukar et al., 2007).

Sistem reaktor DHS didesain untuk diaplikasikan sebagai unit pengolahan air limbah. Reaktor DHS telah dikembangkan juga oleh peneliti yang lain di Universitas Teknologi Nagaoka, Jepang sebagai alat pengolahan limbah domestik yang murah dalam biaya operasi terutama untuk negara-negara berkembang sejak tahun 1995 (Machdar et al., 2000). Penelitian bioreaktor DHS awalnya diterbitkan pada tahun 1997 oleh (Machdar et al., 1997) dan telah dieksplorasi terus menerus setiap waktu oleh banyak peneliti (Araki et al., 1999; Machdar et al., 2000; Machdar and Faisall, 2011; Tandukar et al., 2007, 2006, 2005) untuk pengolahan limbah domestik. Reaktor DHS dapat direkomendasikan sebagai teknologi yang efisien dan hemat biaya untuk pasca pengolahan air limbah kota, terutama untuk negara-negara berkembang seperti penelitian yang telah dilakukan di Mesir (Mahmoud et al., 2011)

Sistem reaktor DHS memiliki performa tinggi dalam memproses lumpur aktif yang dicapai dengan stratifikasi mikroba yang berguna untuk mengurangi senyawa organik dan mengoksidasi amonia dan nitrit di dalam reaktor DHS (Kubota et al., 2013). Sealin itu penelitian yang pernah dilakukan skala pilot plant dengan laju alir $50 \mathrm{~m}^{3} /$ hari menunjukkan kebutuhan energi yang dibutuhkan dan produksi lumpur pada pilot plant tersebut lebih rendah dari pada activity sludge (Tanaka et al., 2012).

Reaktor DHS skala penuh dioperasikan di instalasi pengolahan limbah di Karnal, Haryana Negara, India. Instalasi pengolahan limbah terdiri dari UASB reaktor dan stabilisasi kolam, disebut sebagai Final Polisihing Unit (FPU) di India. Kapasitas disain dari instalasi pengolahan limbah adalah $40.000 \mathrm{~m}^{3} /$ hari (Okubo et al., 2015). Penelitian reaktor DHS pernah dilakukan sebelumnya dimana pengujian hanya tracer esperiment tanpa pengolahn limbah dan memiliki persamaan dimana modul yang digunakan adalah sponge (Machdar, 2016). Tujuan penelitian ini adalah untuk mengevaluasi unjuk kerja bioreaktor DHS dalam mengolah limbah domestik. 


\section{METODOLOGI PENELITIAN}

Bioreaktor skala pilot plant diinstal di Intalasi Pengolahan Lumpur Tinja (IPLT) Banda Aceh. Skema bioreaktor dapat dilihat pada Gambar 1. IPLT menampung sekitar 20.000 liter limbah domestik dari pemukiman Kota Banda Aceh. Bioreaktor DHS dengan tinggi $350 \mathrm{~cm}$ yang terbuat dari tabung acrylic terdiri dari 3 bagian, yaitu tabung paling atas memiliki panjang
$115 \mathrm{~cm}$, tengah $70 \mathrm{~cm}$, dan bawah $145 \mathrm{~cm}$, setiap tabung memiliki jarak $10 \mathrm{~cm}$ yang berfungsi sebagai ventilasi. Menara bioreaktor DHS memiliki volume 160 liter. Modul sponge Bioreaktor DHS dapat dilihat pada Gambar 2. Modul sponge berbahan polyurethene foam (diameter 3 $\mathrm{cm}$ dan tinggi $3 \mathrm{~cm}$ ). Bioreaktor DHS start up tanpa menggunakan seeding dan selama evaluasi, tidak dilakukan backwash dan penggantian modul.

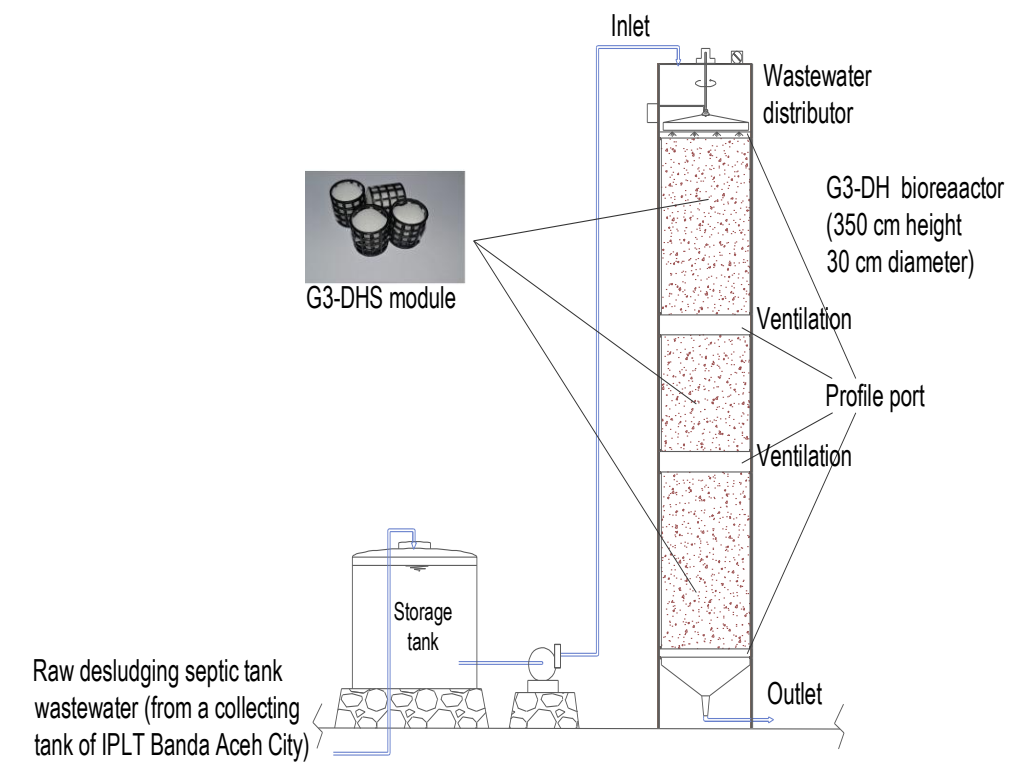

Sumber: dokumen pribadi

Gambar 2. Diagram DHS Bioreaktor

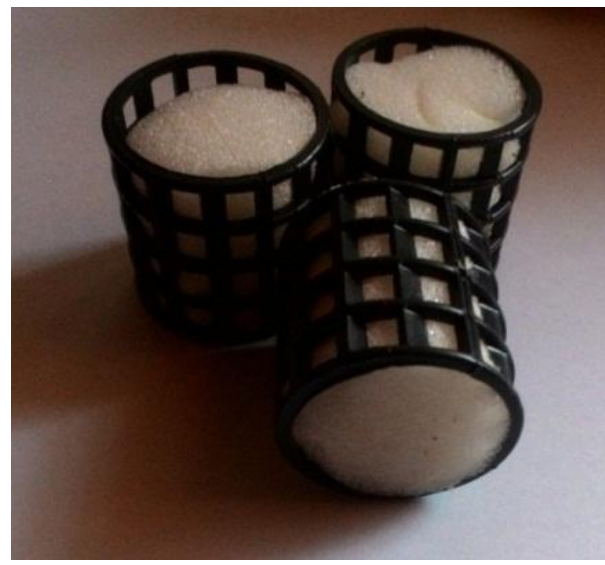

Sumber: dokumen pribadi

Gambar 2. Modul Sponge bersih

\section{Tracer Experiment}

Investigasi kelakuan (behavior) pada bioreaktor DHS dilakukan melalui tracer experiment. Tracer experiment dilakukan dengan menginjeksi cairan yang mengandung bahan inert seperti $\mathrm{NaCl}$ ke dalam bioreaktor DHS. Konsentrasi tracer pada aliran keluar bioreaktor DHS dideteksi dengan conductyvity meter dan dicatat secara manual. Tracer experiment dilakukan pada dua kondisi yaitu pada saat modul sponge dalam keadaan bersih (clean module) sebelum start up dan dalam jangka waktu setiap bulannya. Data yang telah diperoleh dibuat kurva (rentention time distribution) dan actual hydraulic residence time $\left(\mathrm{HRT}_{\mathrm{A}}\right)$ dihitung menggunakan persamaan (1).

$\frac{\Delta N}{N_{0}}=\frac{C v \Delta t}{N_{0}}=P(t) \Delta t($ Levenspiel, 1999)(1) 


\section{Sampling dan Metode Analisis}

Unjuk kerja DHS Bioreaktor dievaluasi dengan menganalisis beberapa parameter yaitu Chemical Oxygen Demand (COD), Biological Oxygen Demand (BOD), Suspended Solid (SS), Volatile Suspended Solids (VSS), Dissolved Oxygen (DO), pH, total nitrogen, ammonia, nitrit, dan nitrat, dengan pengambilan sampel pada bagian inlet dan outlet bioreaktor.

\section{HASIL DAN PEMBAHASAN}

Unjuk kerja bioreaktor DHS tergantung pada adanya mikroba, konsentrasi oksigen terlarut dan efisiensi kontak antara limbah cair dan mikroorganisme. Tingkat pengontakan ini dapat dilakukan dengan mengukur volume efektif atau waktu tinggal limbah cair di dalam bioreaktor. Data yang diperoleh dari tracer study

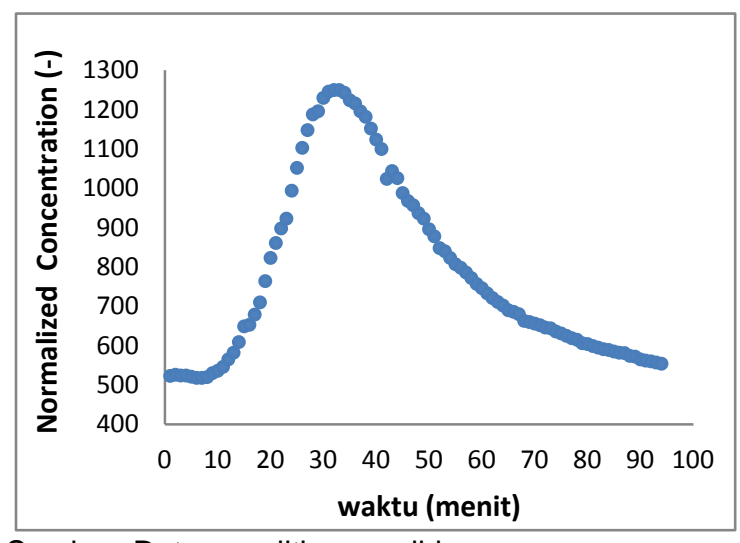

Sumber: Data penelitian sendiri

Gambar 3. Tracer experiment saat start up modul bersih HRT 1 jam

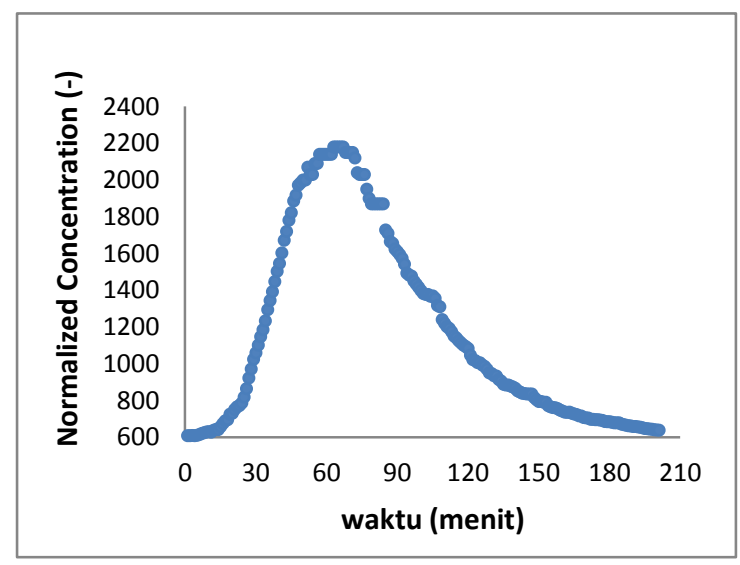

Sumber: Data penelitian sendiri

Gambar 4. Tracer experiment HRT 2 jam bulan keempat dibuat dalam kurva Retention Time Distribution (RTD). Hasil RTD dapat dilihat pada Gambar 3-6. Tabel ringkasan waktu tinggal aktual pada penelitian ini dapat dilihat pada Tabel 1. Tracer study dilakukan pada waktu tinggal teoritis 60 menit, 120 menit, dan 180 menit. Rasio (persentase) antara waktu tinggal limbah teoritis $\left(\mathrm{HRT}_{\mathrm{T}}\right)$ dan waktu tinggal aktual $\left(H R T_{A}\right)$, memberikan gambaran volume efektif dari modul. Diperoleh volume DHS bioreaktor tanpa biomassa sebesar 60\% dan pada kondisi megandung biomassa 70\%-100\%. Berdasarkan hasil tracer study yang dapat dilihat pada Tabel 1 diperoleh $\mathrm{HRT}_{\mathrm{A}}$ tertinggi sebesar 231 menit pada $\mathrm{HRT}_{\mathrm{T}} 4$ jam dan persentase volum efektif tertinggi sebesar $109 \%$ pada $\mathrm{HRT}_{\mathrm{T}} 60$ menit. Volume efektif bioreaktor meningkat dengan menigkatnya waktu operasi bioreaktor. Hal ini disebabkan adanya biomassa yang terperangkap dalam modul.

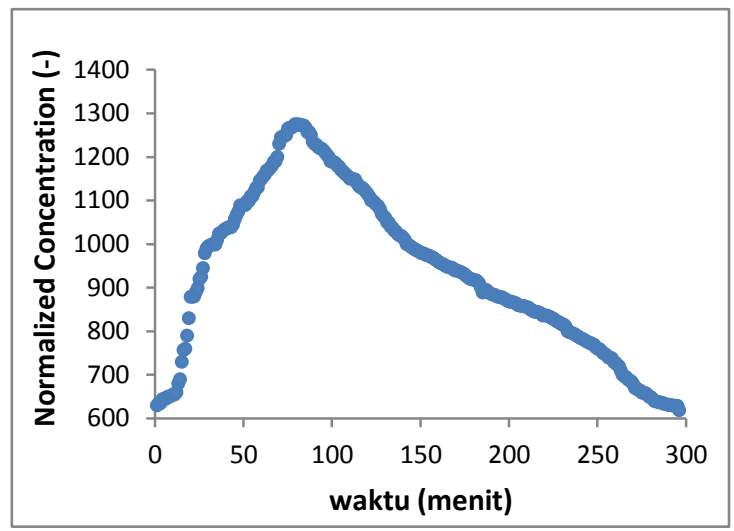

Sumber: Data penelitian sendiri

Gambar 5. Tracer experiment HRT 3 jam bulan kedua

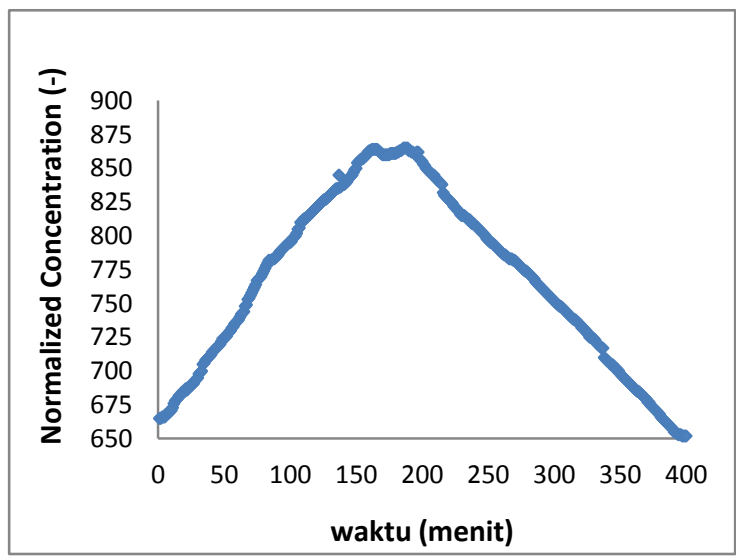

Sumber: Data penelitian sendiri

Gambar 6. Tracer experiment HRT 4 jam bulan kesepuluh 
Tabel 1. Ringkasan hasil tracer study

\begin{tabular}{|c|c|c|c|}
\hline $\begin{array}{l}\text { Waktu Operasi } \\
\text { Bioreaktor }\end{array}$ & $\begin{array}{c}\mathrm{HRT}_{\mathrm{T}} \\
\text { (menit) }\end{array}$ & $\begin{array}{c}\mathrm{HRT}_{\mathrm{A}} \\
\text { (menit) }\end{array}$ & $\begin{array}{l}\text { Volume Efektif } \\
\text { Modul (\%) }\end{array}$ \\
\hline \multirow{2}{*}{$\begin{array}{l}\text { Start Up (modul } \\
\text { Bersih) }\end{array}$} & 60 & 36 & 60 \\
\hline & 120 & 72 & 60 \\
\hline \multirow{2}{*}{ Bulan Kedua } & 60 & 42 & 70 \\
\hline & 180 & 65 & 36 \\
\hline \multirow{3}{*}{ Bulan Ketiga } & 60 & 48 & 80 \\
\hline & 120 & 92 & 77 \\
\hline & 180 & 115 & 64 \\
\hline \multirow{3}{*}{ Bulan Keempat } & 60 & 50 & 83 \\
\hline & 120 & 86 & 72 \\
\hline & 180 & 101 & 56 \\
\hline \multirow{3}{*}{ Bulan Kelima } & 60 & 66 & 109 \\
\hline & 120 & 87 & 73 \\
\hline & 180 & 142 & 79 \\
\hline \multirow{3}{*}{ Bulan Keenam } & 60 & 60 & 100 \\
\hline & 120 & 87 & 73 \\
\hline & 180 & 142 & 79 \\
\hline Bulan Kesepuluh & 240 & 179 & 75 \\
\hline Bulan Kedua belas & 240 & 231 & 96 \\
\hline Bulan Keempat belas & 240 & 182 & 76 \\
\hline
\end{tabular}

\section{Unjuk Kerja DHS Bioreaktor}

Unjuk kerja (performance) dari bioreaktor untuk penyisihan soluble COD, COD, BOD, nitrogen, dan suspended solid dapat dilihat pada Tabel 2. Umpan yang masuk dalam bentuk COD dan BOD masing-masing $416 \mathrm{mg} / \mathrm{L} \pm 142 \mathrm{mg} / \mathrm{L}$ dan $130 \mathrm{mg} / \mathrm{L} \pm 48 \mathrm{mg} / \mathrm{L}$. Bioreaktor dioperasikan pada waktu tinggal 4 jam, setara pembebanan organik sebesar 2,49 $\mathrm{kg} \mathrm{COD} / \mathrm{m}^{3}$ per hari atau $0,78 \mathrm{~kg} \mathrm{BOD} / \mathrm{m}^{3}$ per hari (berdasarkan volume modul sponge). Dari laju pembebanan ini, penyisihan bahan organik yaitu $B O D$ sebesar $80 \% \pm 9 \%$. Effluen BOD yang diperoleh sebesar $26 \mathrm{mg} / \mathrm{L} \pm 15 \mathrm{mg} / \mathrm{L}$. Nilai ini masih di bawah ambang standar Indonesia (100 mg/L). Laju rata-rata ammonia yang diterima bioreaktor $28 \mathrm{mg} / \mathrm{L}$ $\pm 6 \mathrm{mg} / \mathrm{L}$. Penyisihan ammonia dari influen tersebut sebesar $65 \% \pm 24 \%$ dengan effluen yang dihasilkan bioreaktor $11 \mathrm{mg} / \mathrm{L}$ $\pm 8 \mathrm{mg} / \mathrm{L}$. Nitrogen direduksi di dalam bioreaktor secara nitrifikasi. Jumlah total nitrogen $38 \mathrm{mg} / \mathrm{L} \pm 8 \mathrm{mg} / \mathrm{L}$ terjadi penurunan menjadi $16 \mathrm{mg} / \mathrm{L} \pm 7 \mathrm{mg} / \mathrm{L}$ pada penelitian ini. Kemampuan bioreaktor menurunkan SS karena media sponge yang menyediakan ruang tiga dimensi untuk retensi lumpur jauh lebih tinggi dari pada bahan lain (Onodera and Syutsubo, 2015)(Onodera et al., 2015). Konsentrasi oksigen terlarut dalam air limbah adalah salah satu parameter penting dalam proses aerobik. Berdasarkan Tabel 2 dapat dilihat nilai DO pada efluen lebih tinggi dari pada influen yaitu $5,85 \mathrm{mg} / \mathrm{L} \pm 0,21 \mathrm{mg} / \mathrm{L}$. Hal ini menunjukkan konsentrasi larutan oksigen di dalam pola aliran limbah yang melewati permukaan sponge mampu dipertahankan pada konsentrasi tinggi. 
Tabel 2. Ringkasan unjuk kerja DHS bioreaktor

\begin{tabular}{|c|c|c|}
\hline Parameter & Influen & Effluen \\
\hline $\mathrm{pH}$ & $5,3-5,8$ & $6,3-7$ \\
\hline $\mathrm{DO}(\mathrm{mg} / \mathrm{L})$ & $1,9(0,14)$ & $5,85(0,21)$ \\
\hline COD (mg/L) & $416(142)$ & $289(151)$ \\
\hline Soluble COD (mg/L) & $204(90)$ & $142(86)$ \\
\hline $\mathrm{BOD}(\mathrm{mg} / \mathrm{L})$ & $130(48)$ & $26(15)$ \\
\hline Ammonia-N (mgN/L) & $28(6)$ & $11(8)$ \\
\hline $\mathrm{NO} 2-\mathrm{N}(\mathrm{mgN} / \mathrm{L})$ & $0,3(0,4)$ & $0,9(1,1)$ \\
\hline NO3-N (mgN/L) & $4(2)$ & $16(7)$ \\
\hline $\mathrm{TN}(\mathrm{mgN} / \mathrm{L})$ & $38(8)$ & $16(7)$ \\
\hline TSS (mg/L) & $185(56)$ & $132(43)$ \\
\hline VSS (mg/L) & $121(35)$ & $101(38)$ \\
\hline Removal & & \\
\hline Soluble-COD (\%) & \multicolumn{2}{|c|}{$33(12)$} \\
\hline COD (\%) & \multicolumn{2}{|c|}{$34(19)$} \\
\hline BOD (\%) & \multicolumn{2}{|c|}{$80(9)$} \\
\hline Ammonia-N (\%) & \multicolumn{2}{|c|}{$65(24)$} \\
\hline Produksi NOx $\left(\mathrm{kg} / \mathrm{m}^{3}-\mathrm{d}\right)$ & \multicolumn{2}{|c|}{$0,08(0,04)$} \\
\hline HRT (Jam) & \multicolumn{2}{|c|}{4} \\
\hline
\end{tabular}

\section{Profil}

Analisis profil dari aliran air limbah di sepanjang bioreaktor dilakukan dengan menampung air limbah pada bagian inlet dan sekat antara tabung seperti pada Gambar 1. Ditemukan penyisihan organik (soluble COD) secara efektif dari bagian tengah dari bioreaktor $47 \mathrm{mg} / \mathrm{L}$ dimana soluble COD yang masuk sebesar 69 $\mathrm{mg} / \mathrm{L}$.

Penyisihan ammonia (nitrifikasi) terjadi pada bagian tengah dimana ammonia yang masuk sebesar $34 \mathrm{mg} / \mathrm{L}$ selanjutnya terus berkurang pada bagian bawah bioreaktor menjadi 0,09 mg/L. Sedangkan pada bagian atas bioreaktor menunjukkan bahwa sangat efisien dalam menahan padatan dan diikuti biodegradasi oleh bakteri heterotrof. Fenomena ini juga diperoleh oleh peneliti lain (Araki et al., 1999; Machdar et al., 2000; Onodera et al., 2014; Tandukar et al., 2006). Hal ini membuktikan bahwa lingkungan mikroorganime pasti berbeda di sepanjang ketinggian bioreaktor.

\section{KESIMPULAN}

Bioreaktor DHS memiliki potensi untuk menurunkan kadar COD, BOD, ammonia dan TSS limbah domestik. DHS Bioreaktor mampu menyisihkan BOD sampai $80 \%$. DHS Bioreaktor memiliki kemampuan untuk menangkap oksigen yang baik, walaupun bioreaktor ini tidak menggunakan aerator (alat mekanik) sehingga lebih efisien dalam pemakaian energi. Unjuk kerja bioreaktor DHS memenuhi standar mutu buangan limbah Indonesia.

\section{UCAPAN TERIMA KASIH}

Penelitian ini didanai oleh hibah penelitian dari Direktorat Jenderal Pendidikan Tinggi melalui kolaborasi penelitian internasional. Penulis sampaikan terima kasih atas dukungan NIES (National Institute for Environmental Studies) Jepang serta kepada Bapak Dr. Ir. Izarul Machdar M.Eng dan Bapak Syaifullah Muhamad ST, M. Eng sebagai pembimbing dalam menyelesaikan penelitian ini. 


\section{DAFTAR PUSTAKA}

Araki, N., Ohashi, A., Machdar, I., Harada, H., 1999. Behaviors of nitrifiers in a novel biofilm reactor employing hanging sponge-cubes as attachment site, in: Water Science and Technology. pp. 23-31. doi:10.1016/ S0273-1223(99)00146-8.

Kearton, R., Alvarez, V., Setiono, I., Soraya, G., Fook, C., 2013. East Asia pacific region urban sanitation review. Indones. Ctry. Study.

Kubota, K., Hayashi, M., Matsunaga, K., Iguchi, A., Ohashi, A., Li, Y.Y., Yamaguchi, T., Harada, H., 2013. Microbial community composition of a down-flow hanging sponge (DHS) reactor combined with an up-flow anaerobic sludge blanket (UASB) reactor for the treatment of municipal sewage. Bioresour. Technol. 151, 144-150. doi:10.1016/j.biortech.2013. 10.058 .

Levenspiel, O., 1999. Chemical reaction engineering, Department of chemical engineering Oregon state University. 3rd ed. New York, Jhon Wiley and Sons. 277-346. doi:10.1016/00092509(64)85017-X.

Machdar, I., 2016. Hydraulic Behavior in The Downflow Hanging Sponge Bioreactor. J. Litbang Ind. 6, 83-88.

Machdar, I., Faisal, M., 2011. Modification of DHS bioreactor module with oil palm fiber material for treating domestic wastewater. J. Water Environ.

Machdar, I., Harada, H., Ohashi, A., Sekiguchi, Y., Okui, H., Ueki, K., 1997. $A$ novel and cost-effective sewage treatment system consisting of UASB pre-treatment and aerobic posttreatment units for developing countries, in: Water Science and Technology. pp. 189-197. doi:10. 1016/S0273-1223(97)00739-7.

Machdar, I., Sekiguchi, Y., Sumino, H., Ohashi, A., Harada, H., 2000. Combination of a UASB reactor and a curtain type DHS (downflow hanging sponge) reactor as a cost-effective sewage treatment system for developing countries, in: Water Science and Technology. pp. 83-88.

Mahmoud, M., Tawfik, A., El-Gohary, F., 2011. Use of down-flow hanging sponge (DHS) reactor as a promising post-treatment system for municipal wastewater. Chem. Eng. J. 168, 535543. doi:10.1016/j.cej.2011.01.019.

Okubo, T., Onodera, T., Uemura, S., Yamaguchi, T., Ohashi, A., Harada, H., 2015. On-site evaluation of the performance of a full-scale down-flow hanging sponge reactor as a posttreatment process of an up-flow anaerobic sludge blanket reactor for treating sewage in India. Bioresour. Technol. 194, 156-164. doi:10.1016/ j.biortech.2015.07.015.

Onodera, T., Syutsubo, K., 2015. Protection of biomass from snail overgrazing in a trickling filter using sponge media as a biomass carrier: down-flow hanging sponge system. Water Sci.

Onodera, T., Tandukar, M., Sugiyana, D., Uemura, S., Ohashi, A., Harada, H., 2014. Development of a sixthgeneration down-flow hanging sponge (DHS) reactor using rigid sponge media for post-treatment of UASB treating municipal sewage. Bioresour. Technol. 152, 93-100. doi:10.1016/ j.biortech.2013.10.106.

Tanaka, H., Takahashi, M., Yoneyama, Y., Syutsubo, K., Kato, K., Nagano, A., Yamaguchi, T., Harada, H., 2012. Energy saving system with high effluent quality for municipal sewage treatment by UASB-DHS. Water Sci. Technol. 66, 1186-1194. doi:10.2166/ wst.2012.297.

Tandukar, M., Machdar, I., Uemura, S., Ohashi, A., Harada, H., 2006. Potential of a Combination of UASB and DHS Reactor as a Novel Sewage Treatment System for Developing Countries: Long-Term Evaluation. J. Environ. Eng. 132, 166-172. doi:10.1061/(ASCE)0733-9372(2006) 132:2(166). 
Tandukar, M., Ohashi, A., Harada, H., 2007. Performance comparison of a pilot-scale UASB and DHS system and activated sludge process for the treatment of municipal wastewater. Water Res. 41, 2697-2705. doi:10.1016/j.watres.2007.02.027
Tandukar, M., Uemura, S., Machdar, I., Ohashi, A., Harada, H., 2005. A lowcost municipal sewage treatment system with a combination of UASB and the "fourth-generation" downflow hanging sponge reactors. Water Sci. Technol. 52, 323-329. 